\title{
A Fuzzy Logic Approach to Measure Underweight Among Kindergarten's Kids
}

\author{
Balkiah Moktar ${ }^{*}$, Nur Amalina Aziz ${ }^{2}$, Muhamad Hasbullah Mohd Razali Author ${ }^{3}$ \\ ${ }^{1,2,3}$ Faculty of Computer and Mathematical Sciences, Universiti Teknologi MARA (UiTM) Cawangan \\ Corresponding author: *balkiah@perlis.uitm.edu.my \\ Received Date: 2 August 2018 \\ Accepted Date: 12 November 2018
}

\begin{abstract}
Nowadays, being underweight during childhood is equally risky as being overweight. Underweight children lead to decrement in their academic performance, a social problem as well as challenging attitudes. Underweight people are likely to be less fit and active, which would also increase their cardiovascular risk and health problem. Their mind also becomes inflexible while their concentration and ability to decide are markedly weak. The purpose of this study is to evaluate the chances of having underweight among the children by using Fuzzy Logic (FL) Approach. Besides that, the comparison of effectiveness result of underweight between Body Mass Index (BMI) method and FL Approach using Mamdani method will be made. The data of weight and height of the children were collected from 3 kindergartens in Perlis. The result shows that 60 to 70 percent of children having an underweight in a range between $79.1 \%$ to $91.2 \%$ compare to the BMI method that is only 10 percent of children have underweight. It shows that Mamdani method was very effective compared to BMI Method because of the flexibility from the output control that is a smooth control function despite a wide range of input.
\end{abstract}

Keywords: Underweight kids, Fuzzy Logic Approach, BMI, Mamdani method

\section{INTRODUCTION}

This research focuses on measuring underweight of the kindergarten's kids. Underweight is a weight that is below the normal, average, or requisite weight. During early stages and childhood, kids gain weight and grow more rapidly than at any other stage in life. However, some kids do not gain weight at a normal rate, either because of being born prematurely, expected variations related to genes or because of undernutrition, which may occur for the various cause. Undernutrition is defined as the outcome of insufficient food intake such as protein, calories, vitamin, minerals and so on (Martins et al., 2011). Sometimes undernutrition is defined as a failure to thrive or growth deficit problem.

Measuring the growth of a kid is an important part of a child's health care. It can help to recognize underweight and overweight, short stature and faltering growth. It can also provide consolation about normality. The most common method used for measuring the weight status of people is Body Mass Index. In addition, BMI is most commonly used for measuring obesity in adults (Must and Anderson, 2006) but to make a difference in this research, FL Approach will be used to measure the weight status of the selected kids from three different kindergartens in Perlis.

\section{PROBLEM STATEMENT}

Nowadays, childhood obesity is one of the most severe conditions, posing many health risks among the young generation. However, being underweight during childhood is equally risky as being overweight. Fernald \& Grantham-McGregor (1998) reported that underweight children lead to decrement in their 
academic performance, the social problem as well as challenging attitudes. Furthermore, the risks affected by being underweight are often overlooked, and malnutrition leads to increases in health problems among children. For example, bone diseases. Their mind also becomes inflexible while their concentration and ability to make a decision are markedly weak. According to Lazzeri et al. (2008), underweight may also increase the risk of illness, harms the intellectual development and decreases the work productivity in future life. Thus, in this study, the fuzzy logic approach method is proposed to measure underweight among childhood. Fuzzy theory is adapted for analyzing underweight as biologically by using MATLAB.

\section{LITERATURE REVIEW}

\section{Fuzzy Logic (FL) Method}

Dernoncourt (2013) conducted a study to identify what Fuzzy Logic is. He discovered that Fuzzy Logic is a method of computing based on "degrees of truth" rather than the normal "true or false" Boolean Logic on which the modern computer is based. The concept of fuzzy logic was first advanced by Dr. Lotfi Zadeh from the University of California on the 1960s. He also stated that Fuzzy Logic has many theories. Example of Fuzzy Logic theories is Fuzzy set, the linguistic variable, reasoning in Fuzzy Logic and others.

Spada (2009) also conducted a study to learn more about Fuzzy Logic. He divided Fuzzy Logic into two parts which are Fuzzy Logic Broad sense and Fuzzy Logic in Narrow Sense. Thus, he explained that Fuzzy Logic Broad Sense is mainly as tools for fuzzy control, analysis of uncertainty in natural language and several other application fields. He also stated that soft computing is one of the technique in Fuzzy Logic Broad Sense and the example of this technique is computational methods tolerant for sub-optimality and impreciseness that giving simple, good and quick solution. For Fuzzy Logic in Narrow Sense, he defined that it is symbolic logic with a comparative notion of truth.

\section{Weight Status Measurement Using BMI}

World Health Organization (2008) and Butte et al. (2006) conducted a research for measuring a child growth whether the child is growing normally or not. which included biological, theoretical and other issues relating to the development of an international growth reference. Followed by Patel et al. (2015) used BMI for categorizing weight status for each respondent among children and adults in India

Wang et al. (2017) studied on Preschool-Age Chinese Children's Weight Status: WHO Classification, Parent Ratings, Child/Family Characteristics to compare preschool-age Chinese child's weight status according to the World Health Organization guidelines with parental ratings on their child's body type, and child/family demographic representative.

One of the disadvantages of BMI value is it only provides a rough estimation of your body fat but doesn't involve any direct measures of your tissue and finally, it can miscategorized people as healthy.

A normal BMI reading is only one indication of people's health condition. If your daily activities such smoke, practicing the poor diet that contains a lot of sugar and saturated fat, or lack of movement in a day, peoples may still be at risk of health problems. 


\section{METHODOLOGY}

\section{Method of Data Collection}

This study utilized the data collected from teachers of each kindergarten that was mentioned before. Table 1 present the values of weight and height of all student from the selected kindergarten

Table 1: List of weight and height from 3 selected kindergarten in Perlis

\begin{tabular}{|c|c|c|c|c|c|c|c|c|}
\hline \multicolumn{3}{|c|}{$\begin{array}{c}\text { Tabika Kemas Kampung } \\
\text { Surau Dato' Sheikh Ahmad }\end{array}$} & \multicolumn{3}{c|}{$\begin{array}{c}\text { Tabika Kemas } \\
\text { Kampung Darat }\end{array}$} & \multicolumn{3}{c|}{ Tabika Kemas } \\
Alor Gajah \\
\hline Age & $\begin{array}{c}\text { W } \\
(\mathrm{kg})\end{array}$ & $\begin{array}{c}\mathrm{H} \\
(\mathrm{cm})\end{array}$ & Age & $\begin{array}{c}\mathrm{W} \\
(\mathrm{kg})\end{array}$ & $\mathrm{H}(\mathrm{cm})$ & Age & W $(\mathrm{kg})$ & $\mathrm{H}(\mathrm{cm})$ \\
\hline 6 & 19.4 & 117.0 & 4 & 17 & 110 & 4 & 13.5 & 97.0 \\
\hline 4 & 15.6 & 101.0 & 3 & 16 & 104 & 3 & 17.1 & 107.0 \\
\hline 4 & 14.5 & 103.0 & 3 & 17 & 105 & 4 & 16.6 & 105.0 \\
\hline 3 & 13.6 & 95.0 & 4 & 16 & 105 & 3 & 25.2 & 107.0 \\
\hline 4 & 14.5 & 100.5 & 5 & 29 & 105 & 5 & 15.5 & 107.0 \\
\hline 6 & 17.3 & 115.0 & 3 & 18 & 111 & 4 & 14.7 & 97.0 \\
\hline 6 & 16.3 & 109.0 & 5 & 14 & 127 & 4 & 13.5 & 99.0 \\
\hline 3 & 13.8 & 96.0 & 5 & 16 & 96 & 3 & 12.2 & 95.0 \\
\hline 3 & 17.6 & 99.0 & 4 & 15 & 101 & 3 & 12.9 & 96.0 \\
\hline 5 & 30 & 123.0 & 4 & 15 & 96 & 4 & 13.4 & 95.0 \\
\hline
\end{tabular}

\section{Method of Data Analysis}

Fuzzy logic complies such applications perfectly as it relates human decision making with a skill to produce specific solutions from approximate information. Thus, fuzzy system has been used in this study.

\section{Fuzzy System}

Fuzzy system is an alternative to traditional notions of set membership and logic. A fuzzy system can be contrasted with a conventional (crisp) system in three ways:

a. Linguistic Variable

A linguistic variable is defined as a variable where the values are explained in a linguistic term.

\section{b. Fuzzy Conditional Statements}

Fuzzy conditional statements are definitions of the form IF A THEN B, where A and B have fuzzy meaning.

\section{c. Fuzzy Algorithm}

A fuzzy algorithm is an ordered sequence of instruction which involve conditional statements and fuzzy assignment. For an example, IF p is low THEN q is high.

The procedure of fuzzy system includes: 


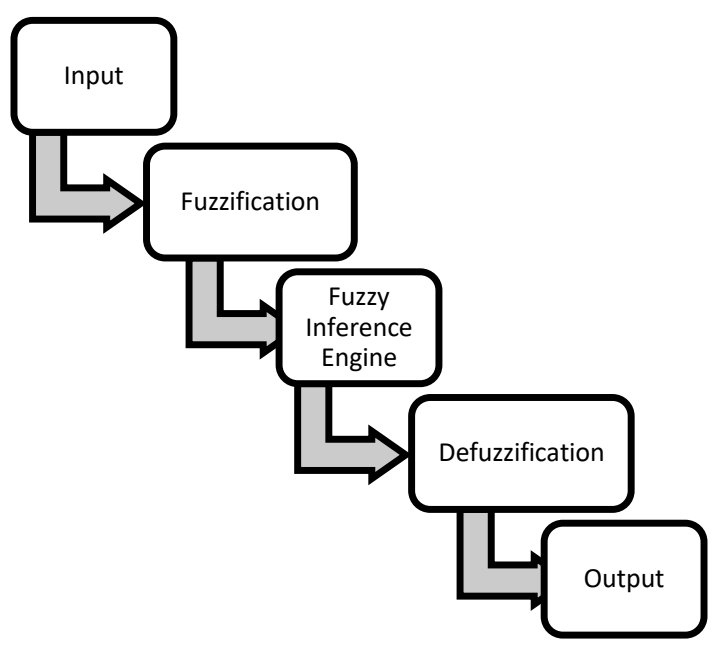

Figure 1: Fuzzy Logic Process

\section{Fuzzy Variables}

A fuzzy variable is the language that will be used to elaborate a fuzzy concept such as weight, height, age and others.

\section{Fuzzification}

Fuzzifier is defined as a crisp point to a fuzzy set while fuzzification is defined as process of converting a crisp quantity into a fuzzy quantity. In fuzzification process, for each input and output variable selected, it will be defined into two or more membership functions, normally three but it can also be more than three. Then, it must be classified into a qualitative category for each of them. Example is low, medium or high.

The shape of these functions can be varied but it normally works with triangular and trapezoidal by following their membership function formula which are

I. Triangular membership function

$$
\mu(x)=\left\{\begin{aligned}
\frac{x-a}{b-a}, & x \leq a \\
\frac{c-x}{c-b}, & b \leq x \leq c \\
0, & c \leq x
\end{aligned}\right\}
$$

II. Trapezoidal membership function

$$
\mu(x)=\left\{\begin{aligned}
0, & x \leq a \\
\frac{x-a}{b-a}, & a \leq x \leq b \\
1, & b \leq x \leq c \\
\frac{d-x}{d-c}, & c \leq x \leq d \\
0, & d \leq x
\end{aligned}\right\}
$$

where $a, b, c$ and $d$ are defined as the range of $x$. 


\section{Fuzzy Membership Functions}

There are two inputs variables include in the fuzzy set which are weight and height and they are classified into fuzzy set. For weight, the input is classified as low, medium and high. The same goes to the height.

\section{Fuzzy IF-THEN Rule}

A fuzzy rule base is a group of fuzzy IF-THEN rules. The basic function of fuzzy rule base is to express the high knowledge in a form of IF-THEN rule structure combined with AND and OR operators. Each fuzzy rule base produced an output of fuzzy set. Besides that, IF-THEN rule statements are used to formulate the conditional statements that comprise fuzzy logic. According to Castillo and Melin (2012), the general form of fuzzy IF-THEN rule is given as:

IF <Input 1> and <Input 2> THEN <Output>, where input and output are fuzzy sets defined in $\mathrm{P}$ is a proper subset of $\mathrm{R}$ and $\mathrm{Q}$ is a proper subset of $\mathrm{R}$.

As for example, the fuzzy logic applies to measure underweight among kindergarten's kids in the following form:

IF height of the kid is less and the weight of the kid is less THEN the chances of the kid getting underweight is high.

In composition-based inference, all rules in the fuzzy rule base are aggregated into a single fuzzy relation that is fuzzy IF-THEN rule by using the Mamdani Combination equation as stated in Eq. 3 .

$$
\mu_{Q_{\mathrm{B}}}=\mu_{\text {Rute }}(x, y)+\mu_{\text {Rupe }}(x, y)+\ldots+\mu_{R u e_{e}}(x, y)
$$

\section{Defuzzification}

Defuzzification is a method where membership functions are used to retranslate the fuzzy output into a crisp value. It is also known as a process to convert the fuzzy output values of a fuzzy inference to a real crisp value.

There are four methods of defuzzified which are:

1. Weight average method

2. Centroid method/ centre of gravity

3. Maximum membership principle or height method

4. Mean-max membership principle or middle of maxima method

In this study, centroid method is used to process defuzzification. This method is regularly used because it has well performance in terms of continuity, counting and computer complexity. Eq. 4 shows the equation of centroid method.

$$
y=\frac{\int \mu_{A}(y) \cdot y d y}{\int \mu_{A}(y) d y}
$$

\section{Mamdani Fuzzy Inference System (MFIS)}

In this study, Mamdani Fuzzy Inference System (MFIS) in Fuzzy Logic was used by applying the data that was collected in MATLAB software. The Mamdani system is suitable when there is a small number of 
variables or input. The advantages of using this method are well suited to human input, has widespread acceptance and instinctive.

\section{Steps in application of the Mamdani Method using MATLAB}

Figure 1 below depicted the process in generating the Fuzzy Logic value in determining the weight status of the children.

\begin{tabular}{|c|c|c|c|}
\hline $\begin{array}{l}\text { Step } 1 \\
\text { Build Fuzzy } \\
\text { Logic } \\
\text { Controller } \\
\text { - Input : } \\
\text { weight, } \\
\text { height } \\
\text { - Output: } \\
\text { chances of } \\
\text { getting } \\
\text { under } \\
\text { weight }\end{array}$ & $\begin{array}{l}\text { Step } 2 \\
\text { Range for } \\
\text { linguistic } \\
\text { variables to } \\
\text { setting up } \\
\text { the } \\
\text { membership } \\
\text { function } \\
\text { (Table } 2 \& \\
\text { 3) }\end{array}$ & $\begin{array}{l}\text { Step } 3 \\
\text { Insert all } \\
\text { possible } \\
\text { rules } \\
\text { - for this } \\
\text { study it has } \\
25 \text { possible } \\
\text { rules }\end{array}$ & $\begin{array}{l}\text { Step } 4 \\
\text { - Identified } \\
\text { the chances } \\
\text { of getting } \\
\text { under- } \\
\text { weight }\end{array}$ \\
\hline
\end{tabular}

Figure 2: Steps in conducting FL Approach

Table 2 provided the range of input used in FL approach while Table 3 are the value of membership function for weight status which derived from the Fuzzy IF-THEN Rule

Table 2: Range for weight and height

\begin{tabular}{|c|c|c|}
\hline Very low & 131619 & 95101107 \\
\hline Low & 161921 & 101107113 \\
\hline Medium & 192225 & 107113119 \\
\hline High & 222528 & 113119125 \\
\hline Very high & 252831 & 119125131 \\
\hline
\end{tabular}

(Sources from Info Kehamilan, Kelahiran, Bayi, Anak dan Keluarga, 2014)

Table 3: Range for chances of having underweight

\begin{tabular}{|l|l|}
\hline Obese & 0025 \\
\hline Overweight & 02550 \\
\hline Normal & 255075 \\
\hline Underweight & 5075100 \\
\hline Risky underweight & 75100100 \\
\hline
\end{tabular}

\section{Body Mass Index (BMI) Calculation}

Body Mass Index formula stated by Nuttall (2015) was weight in kilograms divided by height in meters squared. Then, the weight status of those kids by using BMI calculation is based on BMI percentile range as shown in Figure 2 and Table 4. 

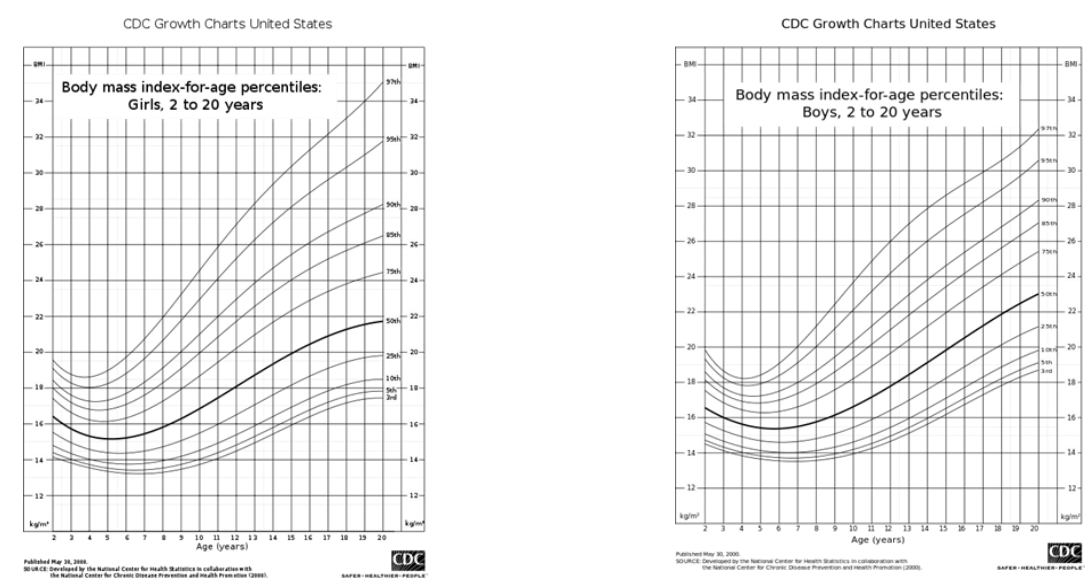

Figure 3: BMI children's chart

(Sources from National Center for Health Statistics in collaboration with the National Center for Chronic Disease Prevention and Health Promotion, 2000)

Table 4: Weight status category for kids

\begin{tabular}{|c|c|}
\hline Weight status category & Percentile range \\
\hline Underweight & Less than the $5^{\text {th }}$ percentile \\
\hline Normal/Healthy weight & 5th percentile to less than the $85^{\text {th }}$ percentile \\
\hline Overweight & 85th to less than the $95^{\text {th }}$ percentile \\
\hline Obese & Equal to or greater than the $95^{\text {th }}$ percentile \\
\hline
\end{tabular}

(Sources from Khalaf et al., 2012)

\section{RESULTS AND FINDINGS}

From Table 5, the result of Tabika Kemas Kampung Surau Dato' Sheikh Ahmad and Tabika Kemas Kampung Darat shows that 6 out of 10 kids having the underweight problem based on FL Approach and only 2 out of 10 kids having the underweight based on BMI calculation. For Tabika Kemas Alor Gajah, 7 out of 10 kids having the underweight problem based on FL Approach but only 1 out of 10 kids having underweight based on BMI calculation.

Thus, the result from 3 selected kindergarten as shown in Table 5 can be concluded as in Figure 3 . There is about $60 \%$ to $70 \%$ of children are underweight in a range between $79.1 \%$ to $91.2 \%$ compared to BMI method that is only $16.67 \%$ of children are having underweight. It shows that FL Approach is more effective compared to BMI Method in identifying the underweight status of the children. 
Table 5: Chances of having an underweight on selected kids from 3 Tabika Kemas (bold shows underweight status)

\begin{tabular}{|c|c|c|c|c|c|c|}
\hline \multirow{2}{*}{ No. } & \multicolumn{2}{|c|}{$\begin{array}{c}\text { Kampung Surau } \\
\text { Dato' Sheikh Ahmad }\end{array}$} & \multicolumn{2}{c|}{ Kampung Darat } & \multicolumn{2}{c|}{ Alor Gajah } \\
\cline { 2 - 7 } & BMI & $\begin{array}{c}\text { FL } \\
\text { Approach (\%) }\end{array}$ & BMI & $\begin{array}{c}\text { FL Approach } \\
(\%)\end{array}$ & BMI & $\begin{array}{c}\text { FL Approach } \\
(\%)\end{array}$ \\
\hline 1 & 14.2 & 60.8 & 14.3 & $\mathbf{8 8 . 8}$ & 14 & 67.5 \\
\hline 2 & 15.3 & $\mathbf{9 1 . 8}$ & 14.9 & $\mathbf{8 0 . 3}$ & 14.8 & $\mathbf{9 0 . 5}$ \\
\hline 3 & $\mathbf{1 3 . 7}$ & $\mathbf{9 0 . 5}$ & 15.1 & $\mathbf{8 3 . 3}$ & 15.4 & $\mathbf{8 0 . 9}$ \\
\hline 4 & 15.1 & 50 & 22.0 & 24.9 & 14.5 & $\mathbf{9 1 . 2}$ \\
\hline 5 & 14.4 & $\mathbf{9 0 . 5}$ & $\mathbf{1 3 . 5}$ & $\mathbf{9 1 . 8}$ & 26.3 & 8.76 \\
\hline 6 & 13.2 & 66.4 & 15.6 & $\mathbf{8 9 . 7}$ & 14.6 & 61 \\
\hline 7 & $\mathbf{1 3 . 7}$ & $\mathbf{7 9 . 1}$ & 13.8 & $\mathbf{8 8 . 8}$ & $\mathbf{8 . 7}$ & $\mathbf{8 9 . 7}$ \\
\hline 8 & 15.0 & $\mathbf{8 8 . 8}$ & $\mathbf{1 3 . 5}$ & 50 & 17.4 & $\mathbf{8 8 . 8}$ \\
\hline 9 & 18.0 & $\mathbf{9 0 . 7}$ & 14.3 & 37.5 & 14.7 & $\mathbf{9 1 . 2}$ \\
\hline 10 & 19.8 & 10.3 & 14.8 & 50 & 16.3 & $\mathbf{8 8 . 8}$ \\
\hline
\end{tabular}

\section{DBMI method DFuzzy method}

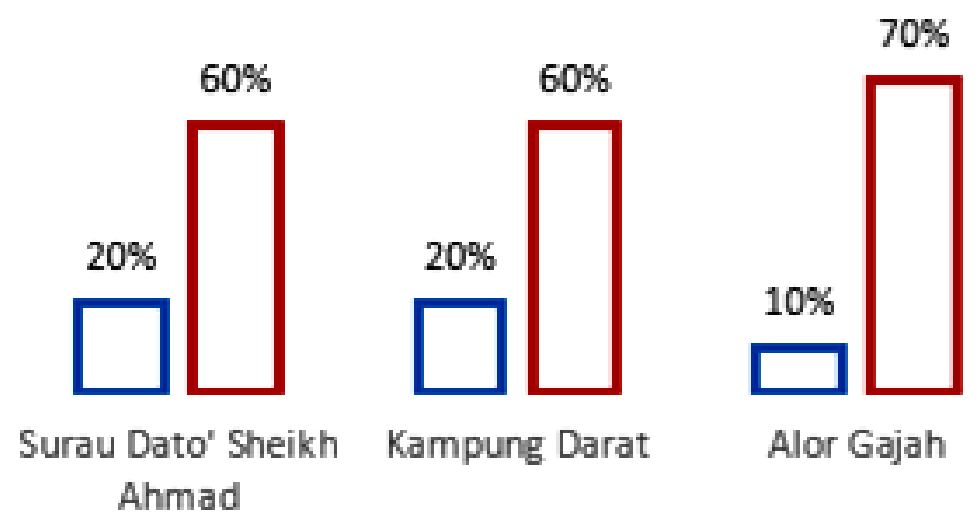

Figure 4: Comparison of percent underweight status between BMI and FL Approach

\section{CONCLUSION}

The result shows that there are more than half kids having an underweight problem from each kindergarten by using FL Approach but only 1 to 2 kids having underweight by using BMI calculation. Therefore, it can be concluded that the FL approach is more effective compared to BMI. This is because the output control is a smooth control function despite a wide range of input and this method is flexible.

For future studies on the subject, several recommendations for improvements are suggested. The fuzzy model calculator should be developed for measuring body weight of people at a different range of age because of its effectiveness in calculation and parents need to ensure their children make healthy food and always get a doctor consultation about their child's weight problem regularly. 


\section{REFERENCES}

Butte, N. F., Garza, C., \& Onis, M. D. (2006). Evaluation of the Feasibility of International Growth Standards for School-Aged Children and Adolescents. Food and Nutrition Bulletin, 27(4). 169-171.

Castillo, O., \& Melin, P. (2012). Type-2 Fuzzy Logic Systems. Recent Advances in Interval Type-2 Fuzzy Systems SpringerBriefs in Applied Sciences and Technology, 7-12.

Dernoncourt, F. (2013). Introduction to Fuzzy Logic. Unpublished master's thesis, Massachusetts Institute of Technology, Cambridge, England.

Khalaf, F. A., Darwish, E. A., \& Katab, M. (2012). Prevalence of Underweight, Overweight and Obesity Among Primary School Children in Qatar. Qatar Medical Journa, 2012(1), 24

Lazzeri, G., Rossi, S., Pammolli, A., Pilato, V., Pozzi, V., \& Giacchi, M. V. (2008). Underweight and overweight among children and adolescents in Tuscany (Italy). Prevalence and short-term trends. Research Centre for Health Promotion and Education, 49, 13-21

Martins, V. J., Florêncio, T. M., Grillo, L. P., Franco, M. D., Martins, P. A., Clemente, A PSawaya, A. L. (2011). Long-lasting effects of undernutrition. International Journal of Environmental Research and Public Health, 8(12), 1817-1846

Must, A., \& Anderson, S. E. (2006). Body mass index in children and adolescents: Considerations for population-based applications. International Journal of Obesity, 30(4), 590-594.

Nuttall, F. Q. (2015). Body mass index. Nutrition Today, 50(3), 117-128.

Onis, M. D. (2009). Growth curves for school-age children and adolescents. Indian Pediatrics, 46, 463465

Patel, S. A., Narayan, K. V., \& Cunningham, S. A. (2015). Unhealthy weight among children and adults in India: urbanicity and the crossover in underweight and overweight. Annals of Epidemiology, 25(5)

Spada, L. (2009). Introduction to Fuzzy Sets and Fuzzy Logic. Retrieved September 17, 2009, from University of Salerno, Department of Mathematics and Computer Science Web site: http://logica.dmi.unisa.it/lucaspada/wpcontent/uploads/foligno_handout.pdf

Unnithan, A.G. \& Syamakumari, S. (2008). Prevalence of Overweight, Obesity andUnderweight among School Going Children in Rural and Urban areas of Thiruvananthapuram Educational District, Kerala State (India). The Internet Journal of Nutrition and Wellness,6(2).

World Health Organization. (2008). Training Course on Child Growth Assessment (Issue Brief No. ISBN 924159507 8). Switzerland: Department of Nutrition for Health and Development.

Wang, G. H., Tan, T. X., \& Cheah, C. S. (2017). Preschool-Age Chinese Children's Weight Status: WHO Classification, Parent Ratings, Child/Family Characteristics. Journal of Pediatric Nursing, 33, 63-69.

Whaley, S. E., Sigman, M., \& Espinosa, M. P. (1998). Infant predictors of cognitive development in an undernourished Kenyan population. Developmental and Behavioral Pediatrics, 19, 169-177. 
